\title{
Research Situation and Development Trends of Distribution Automation Technology
}

\author{
Wei Wang ${ }^{1}$, Weiyuan $\mathrm{Hu}^{1}$, Guowei Zhao ${ }^{1}$, Shengwei Shen ${ }^{1}$, Jidong Shi ${ }^{2}$, Dongju Wang ${ }^{2}$ \\ ${ }^{1}$ State Grid Zhejiang Tongxiang Power Supply Company \\ Tongxiang, 314500, China \\ ${ }^{2}$ College of Electrical Engineering, Zhejiang University \\ Hangzhou 310027, China \\ Correspondence should be addressed to Shi Jidong; jidong_shi@163.com
}

\begin{abstract}
This article has summarized the developing history of distribution automation technology and analyzed existing problems that hinder its practical application. Currently the automation level of the distribution network in our country is very low reflecting as insufficient and immature functions. The research results have shown that the development of distribution automation will be focused on diversification, integration and intellectualization. Considering the intimate connection with smart grid, the article has pointed out the further development trends of distribution automation.
\end{abstract} trend.

Keywords- distribution automation; smart grid; development

\section{INTRODUCTION}

Distribution automation (DA) is the important means to improve power supply reliability, expand power supply area and realize highly effective economic operation of distribution network. The development of smart grid also is also intimately related to the automation level of distribution network.

At the end of the twentieth century and the beginning of the twenty first century, there was an upsurge of distribution automation. New experimental units were built in numbers. Unfortunately these constructions in early times couldn't be widely used because of different kinds of defects and imperfections. After years of trail and error, the technology of distribution automation has made great progress. The rapid development of smart grid brings a high fever of distribution automation system construction.

This article has given a full view of the developing history of distribution automation system in our country based on systematic analysis and detailed comprehension. One step further, the current situation and future aims of distribution automation have also been revealed in the following passages.

\section{CURRENT SituATIONS Of DistribUtion AUTOMATION}

\section{A. Three Stages of Distribution automation development}

The distribution automation technique in our country dates back to the end of 1980s. It is not until middle and later periods of 1990s that experimental projects and project implementation in large scale are carried out. Up to now, the distribution automation technology is still in research and exploration. The development course of DA in our country could be classified into three stages.

(1)Exploration: from the end of 1980s to the beginning of 1990s. At the end of 1980s, state grid in Shijiazhuang and Nantong introduced reclosels and sectionalizers for feeder automation pilot. In 1994, Xiamen power supply bureau built pilots for distribution automation and distribution network information management system. In 1996, Jinteng residential district in Shanghai completed the construction of feeder automation system with cables. At the same time DA system was being applied in Shijiazhuang, Yantai, Yinchuan and other districts.

(2)Pilots in large scale: from the end of 1990s to 2005. In 1997, the outbreak of financial crisis in Asia prompts the large investment in unban power network renovation to stimulate economic development. The state grid corporation put forward the concept of advanced power supply enterprise and tremendously promoted the application of distribution automation. Until 2003, more than one hundred cities at prefecture level and above had built DA system pilots. Among these it is worthy of mentioning that the DA system in Shaoxing Zhejiang province installed nearly five thousand terminals and basically covered the whole distribution network in urban area.

Since 2004, many existed DA systems have been exposed disadvantages of abnormal operation and poor practicality. These problems did remind relative experts of imperfections of current DA systems. Plus the power supply enterprises were busy making up for the absence of power generation. The DA system was not of great importance then. Its development and application entered an ice age.

(3)Smart distribution grid construction: from 2008 to now. Smart distribution grid includes different kinds of new technology on electrical engineering applied in distribution network. Modern computer, communication, measurement control technologies have been adopted to improve the automation level. The DA system belongs to smart distribution gird. As an essential part, its techniques are core components of the smart distribution grid theory. In 2009 the state grid corporation restarted the construction of DA system pilot in Beijing, Hangzhou, Xiamen and Yinchuan. 
In Hangzhou, years of construction and application has formed rich experience. Presently digitalization, Informationization, integration of marketing and distribution and its management have been realized. Distribution automation has already been applied in 132 transmission lines. Similar pilots have also begun to emerge in Shaoxing and other cities.

\section{B. Existing Problems}

(1)Weak distribution network structure. The distribution network in our country is mostly in radiant structure. The feeders are seldom or improperly sectioned. Despite hand-in-hand tie lines have been applied in distribution network, the backup power capacity of feeders is not sufficient to realize continuous power supply for power load transferred to healthy lines during the fault treatment process. Sometimes two hand-in-hand lines come from the same $10 \mathrm{kV}$ bus connected to the same substation, which has negative effects on its flexible power reservation. These defects give limits to the operation modes of distribution system and weaken the ability of responding to emergency situations. The effectiveness of distribution automation system is not satisfying.

(2)Immature technology and facility. The distribution automation system in early times simply duplicated the dispatching automation and power transmission and transformation technology used in main network. The transplantation is arbitrary and not fully considered. The characters of distribution network are neglected. The design and development of main station's functions in distribution automation system lacks pertinence. The power dispatching and management functions almost copied those of main station SCADA, making them impractical and pointless. What's more, the lifetime of terminals used in distribution network couldn't stand the severe environment. The steadiness of system operation is another aspect in need of improvisation. The hardware couldn't live up to the high standards of distribution automation.

(3)Low informatization level of distribution management. Present means of power distribution management are backward and not effective. Without description criteria of informatization and digital model, the distribution network information cannot be exchanged in time. The function application of distribution automation is difficult to realize. On the other hand, graph and data maintenance is not synchronized with the development of network. The accuracy, timeliness and integrality of system data cannot be guaranteed, which makes the DA system unreliable. The model of distribution network is not standard and incomplete. Its application is not optimistic.

(4)GIS (geographic information system) couldn't meet the requirement of dynamic application. GIS is one of the most important fundamental platforms of distribution automation system. It is responsible for network modeling and providing graphs. However, the software designers are not familiar with the process and theory of distribution network management. As a result, GIS is not properly fit for distribution network modeling. The static application might still be smooth but dynamic application like real-time analysis and calculation are not possible. Since there is not any delicate design or feasible plan for models, graphs and interfaces of distribution network SCADA main stations, the long-term use couldn't be accessible.

Generally speaking, the distribution automation level in China is still very low. Only a few districts have realized feeder automation, let alone scale efficiency. The isolated islands of automation and too many specialty divisions hinder the computerization of distribution management process. The practical functions are rather limited.

\section{DEVELOPMENT CHARACTERISTICS AND TARGETS OF DISTRIBUTION AUTOMATION}

\section{A. Development Characteristics}

Judging from the research results until now, the development of distribution automation presents features of diversification, integration and intellectualization.

(1)Diversification. Although the development of distribution automation has experienced three stages, the application of technology in countries has shown that techniques at each stage have their own applicable area. The feeder automation system based on coordination of automatic switchgear equipment is applicable in network with low power load density, long power transmission distance, high fault frequency and low reliability like rural distribution network. The distribution automation system of the second stage is fit for cities of middle size and county towns. The third stage of distribution automation based on artificial intelligence has a lot of advanced functions, which can be utilized in big cities and important areas. Even distribution information system only with functions remote communication and measurement but cannot be remotely controlled has its application prospect. This has to be ascribed to the access to public communication resources like GPRS while saving the construction of specific communication channel.

(2)Integration. The distribution automation refers to many aspects. Some real-time information can be collected by its own collection system. But there is still much real-time and non-real-time information that has to be acquired from other system. For example, the information about main power network and substations comes from the areal dispatch automation system. The topology model and relative graphs about distribution lines come from the GIS system. The facility parameters come from the PMS system. The consumer information comes from the electrical supplying market management system or load control system. Above all, the main station in distribution automation system is no longer a singular real-time monitor 
system. It has to combine several related application systems and forms a synthetic practical system. To standardize interfaces of all application systems, the International Engineering Committee (IEC) has formulated the IEC 61968 series standards and proposed to use the information exchange bus to unite several relative independent and parallel application systems. On one hand, the information exchange will be carried out normally. On the other a whole effective union becomes effective without losing self-characteristics of each application system.

(3)Intellectualization. The distribution power system is an important part of smart grid. Its intellectualization stands for the future of distribution automation. The close connection between distribution automation and smart gird reflects as self healing technology, highly-effective operation technology, integration of distributed generation and energy storage units technology, custom power technology and user interaction technology.

\section{B. Development targets}

According to the characteristics of smart distribution grid, the development targets of distribution automation mainly consist of the following aspects.

(1)Fast fault treatment. When fault happens the distribution automation system should quickly respond to it. Locate and isolate fault area to minimize the district that might be affected. The affected non-fault area should restore power service as soon as possible. The DA system has to be significant to shorten outage time, decrease outage loss, and improve power supply reliability and safety. The large area's service restoration requires application of complicated mathematical algorithms and rapid switch closing and opening operations.

(2)Optimize operation mode of distribution network. The remote measurement function of distribution automation system can be used to monitor the power load distribution of the network. The uploaded data could be evidence for analysis and calculation. When the optimal operation mode is derived, the remote control function could realize network reconfiguration. Other than that, the balance of power load could expand power supply capability. The power loss can be minimized by adopting economic operation mode. The coordinated control of discrete reactive power and power regulation resources are of great use improving power quality.

(3)Integration of relative application systems. The interfaces of distribution system should meet standards of Enterprise Service Bus (ESB) recommended by IEC 61968. The connection with supervisory control and data acquisition (SCADA) system, production management system (PMS) and marketing management system could help improve the intellectualization level of its operation and management.

*Special description of the title. (dispensable)
(4)Integration of distributed generation. Distribution automation should allow safe and sound integration of distributed generation including wind power, photovoltaic power generation, small sized gas turbine, advanced battery system and other types of power generation and storage systems. The integrated systems should be able to operate normally once connected with the DA system. Another problem would be the control of these systems. Especially when distribution network power flow calculation and analysis are involved, the affection of distributed generation could not be ignored.

(5)User interaction. The union with electrical supplying market management system builds a channel that provides bi-directional communication with consumers. The power consumption cost, real-time electricity price, running state of the network, power interruption plan and other service information could be delivered to customers in time. Simultaneously consumers can make their own power consumption plans and take part in the management of power system.

\section{CONCLUSIONS}

The development of distribution automation system in our country has passed over thirty years but still not being prosperous. The existing problems and development directions are crucial and worth of research. This article has pointed out that weak network structure and other aspects like deficient facilities have hindered the further progress of DA system. Diversification, integration with other application systems and intellectualization are important means of improving practicality of DA system. One step further, the distribution automation should be able to realize fast fault treatment and optimization of network operation status. Consideration of new energy resources connecting with power network has put forward new risks for researches of smart grid and distribution automation system.

\section{ACKNOWLEDGEMENT}

Here and now, I would like to extend my sincere thanks to all those who have helped me make this thesis possible and better. Firstly, I am deeply grateful to my honorable colleague, Hu Weiyuan, who has checked through my thesis with patience and given me instructive suggestions, and he also played an important role in indicating a bright road in my future writing. Then thanks to the colleagues and professors who have taught me during the whole process. Finally, I am very grateful to my lovely friends and all those who have offered me quiet situation to compose my thesis and discussed with me about my thesis.

\section{REFERENCES}

[1] Xu Bingyin, Li Tianyou, Xue Yongduan. "Smart distribution grid and distribution automation”. Automation of Electric Power systems, vol. 33, no. 17, pp. 38-41, 2009.

[2] Liu Jian, Zhang Zhihua, Zhang Xiaoqing, Zhao Shuren, Song Xiaolin. "Modeled fault isolation and restoration for distribution 
systems”. Power System Technology, vol. 35, no. 11, pp. 97-102, 2011.

[3] Xu Bingyin and Li Tianyou. "Investigations to some distribution automation issues”. Automation of Electric Power Systems, vol. 34, no. 9, pp. 81-86, 2010.

[4] Liu Jian, Zhao Shuren and Zhang Xiaoqing. "Development of distribution automation in China and some suggestions". Automation of Electric Power Systems, vol. 36, no. 19, pp. 6-10, 2012.

[5] Meng Lei. "Study of improving the power supply reliability of distribution network in Hangzhou”. East China Electric Power, vol. 40, no. 12, pp. 2318-2320, 2012.
[6] Zhao Jianghe, Chen Xin, Lin Tao and Wang Peng. "Distribution automation construction in smart grid". Automation of Electric Power Systems, vol. 36, no. 18, pp. 33-36, 2012.

[7] Shen Bingbing, Wu Lin and Wang Peng. "Technologies characteristics and application effects analysis of distribution automation pilot projects”. Automation of Electric Power Systems, vol. 36, no. 18, pp. 27-32, 2012.

[8] Yuan Wenguang, Zhou Wenjun and Li Chunjian. "Study on real-time SOA for distribution automation system”. Power System Protection and Control, vol. 40, no. 17, pp. 150-155, 2012. 